\title{
The telomerase reverse transcriptase: components and regulation
}

\author{
Constance I. Nugent and Victoria Lundblad ${ }^{\mathbf{1}}$
}

Department of Molecular and Human Genetics, Baylor College of Medicine, Houston, Texas 77030 USA

The idea that chromosomes have special terminal structures first arose as a consequence of experiments conducted by Muller, who found that treatment of Drosophila with X-rays rarely resulted in terminal del etions or inversions of the chromosomes (Muller 1938). Complementary experiments in maize by McClintock expanded upon the idea that tel omeres, the physi cal ends of chromosomes, are required for chromosome stability, by contrasting the breakage-fusion-bridge cycl e resulting from broken dicentric chromosomes with the stability of chromosomes with intact termini (McClintock 1941, 1942). With the dawn of molecular biology, telomeres in most eukaryotes are now known to be composed of short repeated G-rich sequences complexed with proteins to form a special heterochromatin-like structure. More recent experimental manipulation of chromosome termini and of the proteins that bind them have confirmed the early observations of Muller and McClintock, showing that a primary role of tel omeres is to insulate the ends of chromosomes both from fusion with other ends and from nucleolytic digestion (Counter et al. 1992; Sandell and Zakian 1993; Garvik et al. 1995; van Steensel et al. 1998).

$\mathrm{N}$ ot only do telomeres function as protective caps at the ends of chromosomes, but they also facilitate the complete replication of chromosomes. Conventional DNA replication machinery utilizes an RNA primer to initiate DN A synthesis, leading to the problem that extreme terminal sequences will not be represented on the $5^{\prime}$ end of one daughter DNA strand, after removal of a terminal RNA primer. Without a mechanism to replenish these sequences, chromosomes will inevitably shorten as they proceed through successive divisions and, at some point, the ends of chromosomes will be too short to continue to provide the capping function necessary for maintaining genomic stability. The solution to this end-replication problem that has been adopted by most organisms is to use a telomere-specific DNA polymerase called telomerase that extends the $3^{\prime}$ end of the G-rich strand of the tel omere. The synthesis of telomeric DNA by telomerase thereby serves to counter the consequence of semiconservative DNA replication.

${ }^{1}$ Corresponding author.

E-MAIL lundblad@bcm.tmc.edu; FAX (713) 798-5386.
Telomerase was first identified biochemically $>12$ years ago (Grei der and Blackburn 1985) and shown to use an extraordinary mode of synthesis, relying on an intrinsic RN A to serve as a template for the polymerization of the telomeric DNA sequences (Greider and Blackburn 1989; Y u et al. 1990). In the last few years, there has been a substantial advance in our understanding of the additional subunits of telomerase. This review discusses the recent identification and characterization of the reverse transcriptase catalytic component, evaluates the role(s) of other potential protein subunits in telomerase activity or regulation, and concludes with a consideration of the consequences for the cell when telomerase is absent. Regulation of telomerase by the telomere has been the subject of several recent excellent reviews (Brun et al. 1997; Shore 1997) and will not be discussed here.

\section{The RNA subunit of telomerase}

Unlike other polymerases responsible for replication of genomic DN A, telomerase activity depends on an essential RNA subunit. Telomerase was first shown to be an RN A-dependent DN A polymerase by characterization of the enzyme isolated from the unicellular ciliate Tetrahymena. The identification of a 159-nucleotide RNA component containing the sequence $5^{\prime}$-CAACCCCAA$3^{\prime}$, complementary to the $d(T T G G G G)_{n}$ tel omeric repeat synthesized by Tetrahymena telomerase, suggested that this region of the RNA provides a template for telomere synthesis (Greider and Blackburn 1989). Mutational analysis of the CAACCCCAA sequence resulted in an enzyme that synthesized al tered tel omeric repeats, confirming the templating hypothesis ( $\mathrm{Yu}$ et al. 1990; Yu and Blackburn 1991). Since the first discovery in Tetrahymena, tel omerase has now been identified from a wide variety of sources and in every case it has been shown to be a ribonucleoprotein (RNP) complex, with the information that dictates the sequence of the telomere contained within the RNA component.

The templating region of the telomerase RNA can be dissected into two functionally separable subdomains, employed in primer alignment and primer extension (Autexier and Greider 1994, 1995; Gilley and Blackburn 1996). The contributions of different residues of the template to these two functions have been di ssected in detail 
with the Tetrahymena telomerase RNA. These experiments have shown that one end of the RNA template (3'-AAC-5'; see Fig. 1; Table 1) serves to align the telomeric DN A primer for the extension step, via basepairing between the $3^{\prime}$ terminus of the primer and a portion of the template. Subsequent el ongation occurs by copying the remaining six residues of the template onto this telomeric end. These first round products can be further elongated if the new telomeric terminus is translocated back to the primer alignment site, so that the primer is repositioned for another round of synthesis. Although the Tetrahymena enzyme is capable of multiple rounds of elongation from the same telomeric primer (Greider 1991), a processive mode of elongation is not exhibited by all telomerases (Prowse et al. 1993; Prescott and Blackburn 1997a). Processivity is dictated by more than base pairing interactions at the primer alignment site; tel omerase can al so interact with tel omeric substrates at a second, RN A-independent, primer binding site, called the anchor site, that contributes to processive el ongation (M orin 1989, 1991; Harrington and Greider 1991; Collins and Greider 1993; Lee and Blackburn 1993; Melek et al. 1996). Telomerase protein(s) that contribute to anchor site function are discussed in subsequent sections.

Although most tel omerases copy their template regi on faithfully, resulting in telomeres composed of invariant repeats of the same telomeric sequence, a minority of telomerase enzymes synthesize telomeres with an irregular sequence composition (Table 1). This can be attributable to a high frequency of dNTP misincorporation, as appears to be the case for some Paramecium enzymes (M cCormick-Graham et al. 1997), or can be the consequence of stuttering across the templ ate by the enzyme, whereby partial translocation during the synthesis of a single repeat causes dupl icate copying of one or more nucleotides of the template (Yu and Blackburn 1991; Cohn and Blackburn 1995). Saccharomyces cerevisiae telomeres exhibit extreme sequence variability, consist- ing of an irregular repeat conforming to the consensus $\mathrm{T}(\mathrm{G})_{2-3}(\mathrm{TG})_{1-6}$ (Shampay et al. 1984; Wang and Zakian 1990). This foll ows from the possibility of variable positioning of the tel omeric primer al ong the template (Kramer and Haber 1993; Prescott and Blackburn 1997a). Whether the imprecision of these tel omerases can be attributed solely to features inherent in the RNA subunit is not clear. For example, although the S. cerevisiae enzyme has a long template compared to that of many other telomerases (Table 1 ), other budding yeasts with even longer template domains synthesize telomeres composed of regular repeats (M cEachern and Blackburn 1994, 1995).

Although the RNA performs a highly conserved function that is central to the polymerization mechanism, there is very little conservation at the primary sequence level among the telomerase RNAs cloned from $>25$ different species. For example, telomerase RN As from the hypotrichous versus the tetrahymenine ciliates are so diverged that, with the exception of the template region and an adjacent short region, the primary sequences cannot be al igned readily (Lingner et al. 1994), and even the murine and human RNA subunits show only $65 \%$ sequence identity (Blasco et al. 1995; Feng et al. 1995). Despite divergence of the primary sequence of the RN A subunit, the secondary structure has apparently been more conserved; phylogenetic sequence comparison of telomerase RNAs from evolutionarily distant ciliates has led to several related secondary structure proposals (Romero and Blackburn 1991; ten Dam et al. 1991; Lingner et al. 1994; M cCormick-Graham and Romero 1996). A common feature of these models is the proposal that the template region is present as an unpaired region of RNA, consistent with the expectation that it is accessible for the polymerization reaction (Fig. 1). Additional structural features include a highly conserved stem I, thought to establish the superstructure of the RNA, a pseudoknot and a set of stem-loop structures that could
Figure 1. Secondary structure model for telomerase RNA. This representation of a minimal secondary structure for telomerase RNA was proposed from comparative sequence analysis of a number of Tetrahymena species (Romero and Blackburn 1991; ten Dam et al. 1991). The potential pseudoknot structure involving stem-loop III is indicated by the straight lines (top). The three boxed residues AAC $\left(3^{\prime}-5^{\prime}\right)$ align the telomeric end, and the following six boxed residues CCCAAC $\left(3^{\prime}-5^{\prime}\right)$ template nucleotide addition. Helix II is not found in other ciliate RN As (Lingner et al. 1994), and a novel fifth helix is present between helices I and III in Paramecium RN As (M CCormick-Graham and Romero 1996).

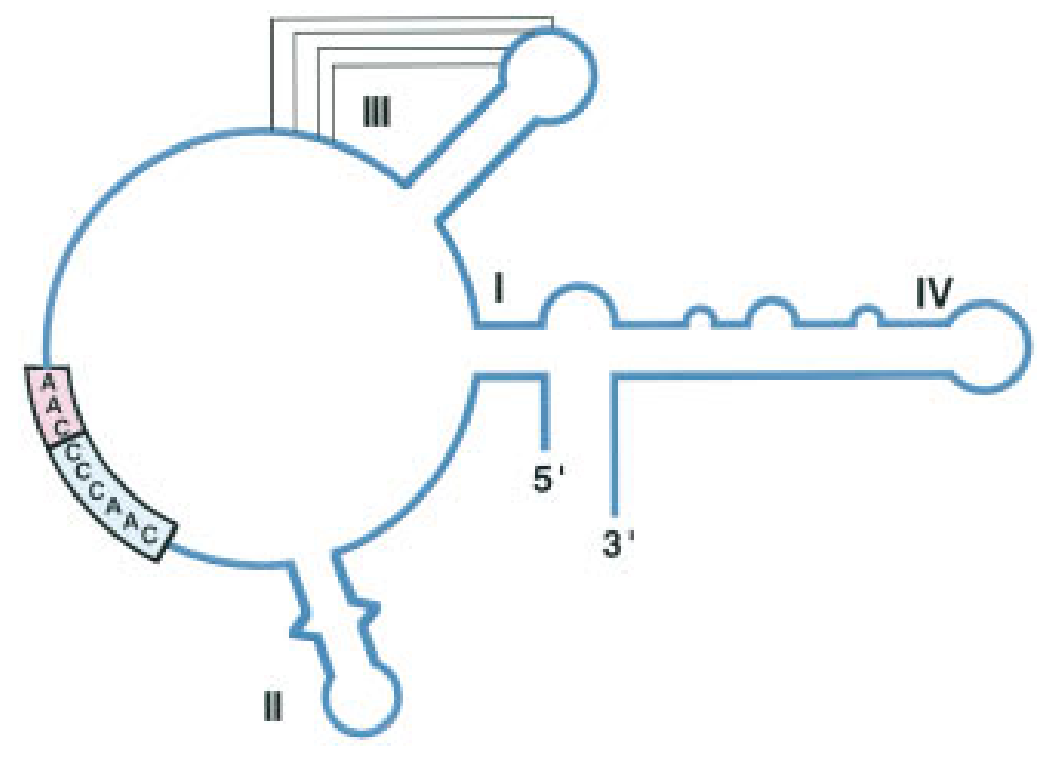


The telomerase reverse transcriptase

Table 1. A comparison of the sequence of the RNA template region and the corresponding telomeric repeat synthesized by six different telomerases

\begin{tabular}{|c|c|c|c|}
\hline Organism & RNA Template $\left(3^{\prime}-5^{\prime}\right)$ & Telomeric Repeats $\left(5^{\prime}-3^{\prime}\right)$ & Reference \\
\hline Tetrah & AACCCCAAC & $($ GGGTTG) & Greider and Blackburn (1989) \\
\hline H. sa & САATСССААТС & $(\text { GGGTTA })_{n}$ & Feng et al. (1995) \\
\hline M. musculus & ТСССААТС & $(\text { GGGTTA })_{n}$ & Blasco et al. (1995) \\
\hline Paramecium & ACСССAAC & (GGGTTG or GGTTTG) $n$ & $\begin{array}{l}\text { McCormick-Graham and Romero } \\
\text { (1996) }\end{array}$ \\
\hline S. cerevisiae & ACACACACCCACACCAC & {$\left[\mathrm{T}(\mathrm{G})_{2-3}(\mathrm{TC}\right.$} & Singer and Gottschling (1994) \\
\hline K. lactis & AAACTAATCCATACACCACATGCCTAAACT & (ACGGATTTGATTAGGTATGTGGTGT) $n$ & McEachern and Blackburn (1995) \\
\hline
\end{tabular}

The RN A template is shown $3^{\prime}$ to $5^{\prime}$, for ease of comparison with the tel omeric repeat synthesized by the respective enzyme. Although the Tetrahymena tel omeric repeats are conventional ly written (GGGGTT) ${ }_{n}$, they are shown here as the permutation (GGGTTG) emphasize the order of synthesis of these six nucleotides by the templating residues after al ignment of the primer. The residues of the Tetrahymena template that are used for substrate alignment are underlined. The sequences of the template regions of other telomerases are derived from sequence inspection of the RNA and comparison to the telomeric repeat synthesized by the respective enzymes. However, the precise $5^{\prime}$ and $3^{\prime}$ boundaries of these additional templates have not yet been determined (although the templates of theS. cerevisiae and Paramecium enzymes have been investigated in some detail by mutagenesis; Prescott and Blackburn 1997b; M cCormick-Graham et al. 1997). For example, it is not clear whether the 3-nucleotide difference between the length of the proposed mouse and human templates represents a functional difference, nor has it been shown that all of the nucleotides 3'-CAAT-5' in the human RNA are utilized in substrate alignment. dNTP misincorporation at the residue indicated in boldface type in the Paramecium template has been proposed to account for the mixture of TTTGGG and TTGGGG repeats observed in vivo in Paramecium tetraurelia telomeres (McCormick-Graham et al. 1997).

contribute to telomerase assembly and/or function by providing potential tel omerase protein binding domains. Probing the native RNA structure through chemical modification of the Tetrahymena telomerase RN P complex has provided data consistent with the proposed structural model, although the structure of the naked RNA appears to be somewhat different (Battacharyya and Blackburn 1994; Zaug and Cech 1995). Functional support for a conserved RNA structure has al so come from cross-species swap experiments, using RN As that are $25 \%-50 \%$ divergent: Chimeric telomerases assembled in vivo with proteins from one species and the telomerase RNA from another are still capable of synthesizing telomeric repeats (Bhattacharyya and Blackburn 1997; McCormick-Graham et al. 1997).

One caveat to the model shown in Figure 1 is that it is a static structure, which contrasts with the conformational change that presumably occurs in response to repositioning of the primer rel ative to the template as telomeric DNA synthesis proceeds. Lingner et al. (1994) have proposed that a conversion between the conserved pseudoknot and the stem-loop III structure could serve as a conformational switch, and structural probing data are consistent with formation of the pseudoknot when the template is unoccupied (Zaug and Cech 1995). This hypothesis has been tested in vitro using partial reconstitution of the telomerase complex, by nuclease digestion of the native RNA and replacement by in vitrotranscribed telomerase RNAs; in this assay, telomerase reconstituted with RNA mutated to abolish the pseudoknot structure still retains wild-type levels of enzyme activity (Autexier and Greider 1998). This same approach also showed that helices III and IV are similarly dispensable for enzyme catalysis. The conservation of these structures, however, suggests that they may be critical in vivo, perhaps by providing binding sites for proteins that confer essential regulatory functions.
The secondary structure described above has not been extended to distant species, such as the much longer telomerase RN As from budding yeast $(1.3 \mathrm{~kb}$ for $\mathrm{S}$. cerevisiae and Kluyveromyces lactis compared to 147-191 bases for the ciliates). In addition, in vivo observations combined with experimental manipulation indicate that sequences between the template region and the $5^{\prime}$ terminus of the RNA are not essential for mammalian tel omerase function. The template domain of the ciliate RN As are located 35-49 nucl eotides from the $5^{\prime}$ end and, consistent with the involvement of the $5^{\prime}$ end in the conserved stem I (Fig. 1), removal of 15 nucleotides from the $5^{\prime}$ terminus of the Tetrahymena RNA abolishes telomerase activity (A utexier and Greider 1998). In contrast, although the template sequence of the human RNA is similarly located 45 nucleotides from the $5^{\prime}$ terminus, removal of the first 43 nucleotides only partially reduces human telomerase activity (Autexier et al. 1996). This experimental observation with the human RN A paral lels the observation that the natural $5^{\prime}$ terminus of the mouse tel omerase RN A occurs only 2 nucleotides before the template (Hinkley et al. 1998). Greider and coll eagues have suggested that the variation in template position between the mouse and the human RN A, and the resulting differences in RNA structure, may contribute to the differing degrees of in vitro processivity exhibited by the two enzymes.

Finally, in addition to alignment and templating functions, several observations indicate that the template region of the RNA directly participates in enzyme action by contributing to both the structure and function of the enzyme active site. Several different singl e base changes in the template of the Tetrahymena RNA result in loss of enzyme fidelity: The insertion of a single $C$ residue in the template results in an enzyme that both in vitro and in vivo displays extreme stuttering, adding multiple se quential dG residues, whereas other template mutations 


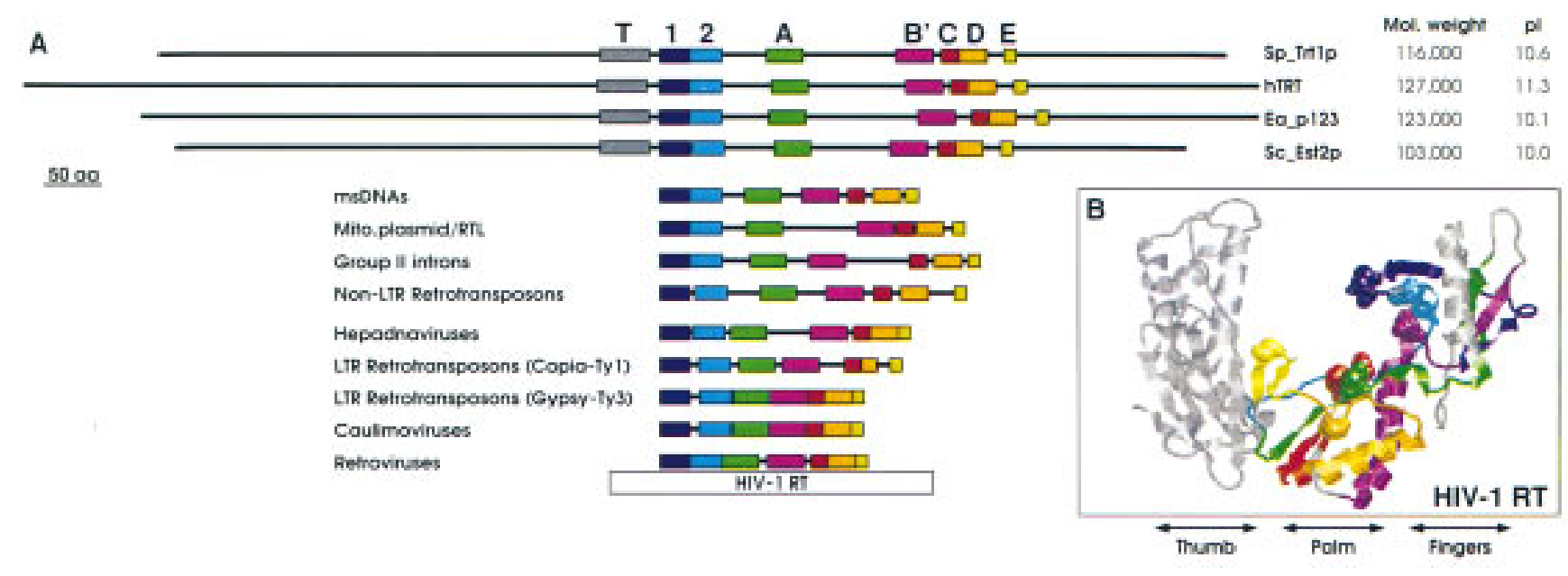

Figure 2. Comparison of protein structural features in tel omerase catalytic subunits with other RTs (reprinted, with permission, from Nakamura et al. 1997, American Association for the Advancement of Science). (A) The locations of the seven sequence motifs conserved in RTs (1, 2, A, B', C, D, and E, defined by Xiong and Eickbush 1990), are indicated by the colored boxes. The gray box indicates the domain uniquely found in telomerases (motif T, $\mathrm{N}$ akamura et al. 1997). The entire lengths and isoelectric points (pl) of the tel omerase proteins are represented; the contributions that domains outside of the RT motifs make to tel omerase function have yet to be defined in detail. For the other polymerases, only the region encompassing the RT motifs is shown. The open box labeled HIV-1 RT (human immunodeficiency virus type I) RT indicates the portion of this protein depicted in B. (B) The crystal structure of the HIV-1 RT p66 subunit is shown as viewed from the back of the right hand (Brookhaven code $1 \mathrm{HN}$ ). This structure has been color coded as in A to show the spatial arrangement of the RT motifs.

lead to dNTP misincorporation (Yu and Blackburn 1991; Gilley et al. 1995). In addition to these effects on fidel ity, template mutations can al so result in premature product dissociation (Gilley et al. 1995). Thus, specific residues of the RNA template may collaborate with telomerase protein(s) to form an optimal active site architecture.

\section{The catalytic subunit of telomerase is a reverse transcriptase}

The dependence of telomerase polymerase activity upon RNA formally defined the enzyme as a specialized type of reverse transcriptase (RT). During the last year, the discovery of the long-sought-after catalytic component of telomerase revealed that it is in fact a reverse transcriptases, related to known RTs by both amino acid sequence and presumably by evolution. This has provided a key step toward a detailed understanding of the mechanism of chromosomal DNA synthesis by telomerase. Identification of this telomerase protein resulted from convergence of complementary biochemical and genetic strategi es in the ciliate Euplotes aediculatus and the yeast S. cerevisiae. In Eupl otes, biochemical fractionation of the enzyme identified two telomerase subunits, p123 and p43, that extensively copurify with telomerase activity and are in apparent stoichiometrically equivalent ratios with the RNA subunit (Lingner and Cech 1996). An independent genetic approach recovered four yeast EST (ever shorter telomeres) genes that, when mutated, confer a telomere replication phenotype in vivo (Lundblad and Szostak 1989; Lendvay et al. 1996). Comparison of the sequence of the yeast 103-kD Est2 protein with the Euplotes p123 subunit revealed that these two proteins are homologs, sharing $\sim 20 \%$ sequence identity and more extensive sequence similarity over the length of both proteins. M ost notable was the presence in both of a set of motifs common to RTs, marked by the presence of a number of highly conserved residues (Lingner et al. 1997a). A subset of these amino acid sequence motifs had previously been shown to form a conserved protein fold comprising the active site of reverse transcriptases (Kohlstaedt et al. 1992; Arnold et al. 1992; JacoboMolina et al. 1993), with three invariant aspartates that are thought to be critical for catal ysis (Fig. 2; Larder et al . 1987; Boyer et al. 1994). Single amino acid changes introduced into the comparable aspartates of the Est2 protein abol ished yeast telomerase activity in vitro and conferred an in vivo tel omere replication defect, demonstrating that these residues are essential for telomerase catalysis (Counter et al. 1997; Lingner et al. 1997a).

Rapid on the heels of the characterization of the telomerase catalytic subunit in Euplotes and yeast has been the identification of the same component in Schizosaccharomyces pombe ( $N$ akamura et al. 1997) and in humans (Harrington et al. 1997b; Kilian et al. 1997; M eyerson et al. 1997; N akamura et al. 1997; N akayama et al. 1998). These proteins, like those from S. cerevisiae and Euplotes, al so show sequence and mechanistic similarity with known RTs, and hence this protein subgroup has been named TERT (telomerase reverse transcriptases). ${ }^{1}$ The TERT protein family is most similar in se-

\footnotetext{
${ }^{1}$ The human protein and gene have been referred to previously as hTRT (telomerase reverse transcriptase) ( $\mathrm{N}$ akamura et al. 1997); hEST2 (M eyerson et al. 1997); hT CS1 (telomerase catalytic subunit 1; Kilian et al. 1997); and TP2 (telomerase protein $\underline{2}$, Harrington et al. 1997b).
} 
quence to RTs such as non-LTR retrotransposons and group II introns that, like tel omerase, extend their RNAtemplated polymerization from DN A 3' hydroxyl primers. However, despite the overall similarities with RNAdependent polymerases, including the three aspartate residues required for enzyme catalysis, telomerases from di sparate organi sms are more rel ated to one another than to other polymerases and thus appear to form a distinct subgroup (Eickbush 1997; N akamura et al . 1997). Several features distinguish telomerase RTs, such as a unique region of sequence conservation termed the "T motif," as well as a large amino-terminal basic domain (Lingner et al. 1997a; Nakamura et al. 1997). Compared with known RNA-dependent polymerases, telomerases also appear to have more residues intervening between motifs $A$ and $B$ '. This suggests that the "finger" region of telomerase, a domain in which the HIV RT interacts with its template (Kohlstaedt et al. 1992; Jacobo-M olina et al. 1993), may have functionally distinct properties.

These variations in the features of the telomerase RT motifs may reflect the obvious mechanistic differences between this enzyme and conventional RTs. Whereas RTs are capable of copying long stretches of RN A molecules, the catal ytic reaction of telomerase differs in that it is restricted to using only a small portion of its RN A subunit as a template, with the borders of the telomerase RNA template region tightly defined. However, under certain in vitro conditions, the HIV RT can be made to stutter, such that repetitive stretches of the same templated base are synthesized to produce a homopolymeric product (Ricchetti and Buc 1996). Whether this perturbation of the RT mechanism, which depends on extensive primer misalignment, is representative of that normally used by telomerase will require further study; as described above, experimental manipulation of telomerase can also cause stuttering (Yu and Blackburn 1991; Gilley et al. 1995). It will be of substantial interest to compare the tertiary structure of telomerase to that of other RN A-dependent polymerases.

Recent investigations with the human TERT protein have led to several insightful observations; these experiments promise to reveal future details about the core enzyme as well as the in vivo regulation of telomerase in human cells. M ost normal cells have undetectable levels of telomerase activity and also fail to express hTERT. Strikingly, enzyme activity in telomerase-negative human cell lines can be restored by the ectopic expression of hTERT (Weinrich et al. 1997; Counter et al. 1998; N akayama et al. 1998). Thus, the catalytic protein is the only limiting factor for telomerase activation in at least a subset of normal human cells, suggesting that regulation of hTERT expression may be a key target during cellular immortalization. By restoring tel omerase activity to normal cells, this technique also has laid the groundwork for assessing whether conversion to telomerase proficiency can reverse the mortal growth characteristics of normal cells; this experiment is discussed in a later section.

A complement to these in vivo experiments is the demonstration that coexpression of the hTERT protein and the human telomerase RNA in reticulocyte lysates is capable of reconstituting enzyme activity (Weinrich et al. 1997; Beattie et al. 1998). This observation suggests that the core enzyme complex may consist of only two components, the RN A and the telomerase reverse transcriptase protein, al though in the absence of reconstitution with purified factors, it is not possible to rule out a contribution of additional components from the lysate. However, the availability of this in vitro reconstitution assay has al ready allowed rapid functional tests of these two components of the core complex, such as dissection of the RNA subunit (Beattie et al . 1998) and the demonstration that the T motif, specific to the telomerase RTs, is required for enzyme activity (Weinrich et al . 1997). An additional consequence is that this in vitro system may accel erate the search for inhibitors of telomerase activity; such inhibitors will be critical in testing the hypothesis that telomerase reactivation plays a role in oncogenesis. Subsequent isolation of derivatives of the core complex that are resistant to such inhibitors could facilitate further the mechanistic dissection of telomerase.

Prior to cloning of any of the TERT proteins, crosslinking studies with Eupl otes telomerase indicated that the large subunit of the enzyme (presumably corresponding to the p123 catalytic component) contains a second site for telomeric DNA binding, called the anchor site (Hammond et al. 1997). The anchor site had been functionally defined by studies showing that primer recognition and processivity of the telomerase enzyme are influenced by the presence of G-rich telomeric sequences at the $5^{\prime}$ end of the primer, even when the $3^{\prime}$ terminus is nontel omeric (M orin 1989, 1991; Harrington and Greider 1991; Lee and Blackburn 1993; Melek et al. 1996). This site is distinct from the binding that occurs between the $3^{\prime}$ end of the DN A primer and the template region of the RNA. Positioning the $5^{\prime}$ end of the primer in the anchor site is thought to contribute to processivity by preventing dissociation of the primer from the enzyme during translocation on the RNA template of the newly extended 3' terminus. In studies with the Euplotes enzyme, in which the $3^{\prime}$ end of the primer was bound in the active site, cross-links between DNA and protein were local ized $20-22$ residues from the 3 ' end, consistent with the prediction for an anchor site interaction with its primer (Hammond et al. 1997). Intriguingly, the use of partially duplex substrates with 3' single-strand overhangs, which should resemble natural telomeres more closely, led to cross-links between protein and the duplex portion of the substrate. As expected, cross-links between the catalytic protein subunit and the telomerase RN A were also observed.

\section{Potential additional components of telomerase}

It is likely that telomerase, like most other polymerases, will consist of a core enzyme associated with other factors to form a holoenzyme complex. These additional factors may provide critical roles such as recruiting and regulating the interaction of telomerase with the telomere. Other hol oenzyme components may modul ate en- 
zyme activity, such as processivity or the stabilization or dissociation of primer/template interactions. Candidates for additional telomerase subunits discussed in this section have come from several different sources, again relying on both genetic and biochemical approaches.

The first telomerase-associated proteins were identified by biochemical fractionation of telomerase from Tetrahymena (Collins et al . 1995). Two proteins, p80 and p95, were recovered by copurification with enzyme activity and the telomerase RNA. Although neither p95 nor p80 appears to encode the catalytic subunit of the Tetrahymena enzyme, they do have biochemical properties consistent with roles in recognition of the DN A substrate and interaction with the telomerase RNA (Collins et al. 1995; Gandhi and Collins 1998). Mammalian homologs of p80 have also been identified as telomeraseassociated proteins (Harrington et al. 1997a; N akayama et al. 1997); a mammalian p95 homolog has not been recovered. Antisera to p80 or its homologs can immunoprecipitate telomerase activity (Collins et al. 1995; Harrington et al. 1997a; Nakayama et al. 1997), and the human p80 homolog is in a complex with the hTERT subunit (Harrington et al. 1997b), demonstrating that the p80 protein is associated with telomerase in vivo in disparate organisms. It remains to be determined whether either p80 or p95 is essential for telomerase activity in vivo. In vitro, in the absence of the stringent demonstration that addition of p80 or p95 changes the biochemical properties of a core enzyme complex, the evidence that p95 and p80 are components of telomerase rests on copurification with enzyme activity and the biochemical properties of the individual proteins.

Recent experiments with Tetrahymena p80 and p95 proteins purified from Escherichia coli have shown that each subunit is independently capable of RN A binding activity, although the complex of both proteins has a substantially greater affinity for RNA (Gandhi and Collins 1998). Although binding is not specific for telomerase RNA, similar attempts to achieve specificity by monitoring the association between a synthetic telomerase RN A and purified telomerase depleted of its endogenous RN A have also not yet succeeded. Cross-linking between p80 and the telomerase RN A can be observed with the purified enzyme (Collins et al. 1995) and the murine p80 homolog can associate with its telomerase RNA, as shown by a three-hybrid interaction (Harrington et al. 1997a), supporting the association of this protein with the telomerase complex. Purified p95 also exhibits specific binding to single-stranded telomeric DN A substrates, in contrast to its nonspecific in vitro RNA binding behavior. The binding preference of p95 for different tel omeric DNA substrates roughly correl ates with the specificity of primers that telomerase can el ongate in vitro, although p95 binding does not exhibit a requirement for a free 3' end (Gandhi and Collins 1998). Crosslinking between the p95 subunit and telomeric primers has also been detected in the context of the purified endogenous enzyme (Collins et al. 1995). These properties suggest that p95 may play a role in substrate recognition in the holoenzyme, possibly by providing the proposed protein anchor site. However, cross-linking between p95 and telomeric substrates does not depend on an intact enzyme complex, as nuclease treatment that abolishes telomerase activity via digestion of the RNA subunit does not abolish cross-linking. In contrast, complexes between tel omerase and tel omeric substrates, by assayed gel mobility shifts, require an intact enzyme; consistent with this RNA-dependent interaction, an RNase-sensitive cross-link between a 100-kD Tetrahymena telomerase protein and elongated telomeric primers has been observed (Harrington et al. 1995). This raises the possibility that p95 could be a telomerase-associated protein that does not depend on its association with telomerase for telomere DNA binding.

In S. cerevisiae, genetic screens for mutants with a telomere repli cation defect have led not only to the identification of the EST 2 gene, encoding the RT subunit of telomerase, but also to other factors involved in telomere replication (Lundblad and Szostak 1989; Lendvay et al. 1996). The three additional proteins (encoded by EST 1, EST3, and EST 4/CDC13) may function as components of the holoenzyme or as potential regulatory factors involved in telomerase function. A separate genetic screen, probing another aspect of telomere function, uncovered TLC1, encoding the yeast telomerase RN A subunit (Singer and Gottschling 1994). Strains carrying deletions of EST 1, EST2, EST3, or TLC1 exhibit the in vivo phenotypes predicted for a telomerase defect (telomere shortening and progressive loss of viability, termed yeast cellular senescence), and epistasis tests have shown that these four genes act in a single pathway for telomere replication (Lundblad and Szostak 1989; Lendvay et al. 1996; Lingner et al. 1997b). However, despite genetic arguments that the role of these genes is in the tel omerasemediated pathway for telomere replication, only mutati ons in EST2 and TLC 1 abolish tel omerase activity in an in vitro assay (Cohn and Blackburn 1995; Counter et al. 1997; Lingner et al. 1997a). Extracts prepared from the other est ${ }^{-}$mutant strains still retain activity at levels roughly comparable to that observed in extracts prepared from a wild-type strain (Cohn and Blackburn 1995; Lingner et al. 1997b). Therefore, the additional EST genes cannot encode components of the catalytic core of the enzyme, but this does not exclude the possibility that these genes encodeholoenzyme subunits that are critical in vivo but dispensable in vitro. Consistent with potential roles as holoenzyme components, the TLC1 tel omerase RNA component can be coimmunoprecipitated with Est1p, Est2p or Est3p (Lin and Zakian 1995; Steiner et al. 1996; Lingner et al. 1997b; T. Hughes and V. Lundblad, unpubl.). However, a substantial caveat to these immunoprecipitation experiments is that the Est proteins are present at such low levels that they cannot be detected in the starting extract, and, as a result, the stoichiometry of each protein relative to the RN A cannot be monitored. Thus, other approaches will be necessary to determine whether these proteins are integral components of the enzyme complex or are more transiently associated with tel omerase. 
Insight into the role of the Estl protein has come from analysis of protein partially purified from an E. coli expression system, in isolation from other potential tel omerase subunits (Virta-Pearlman et al . 1996). Est1 protein binds in vitro specifically to single strand G-rich telomeric DNA, with a requirement for a free $3^{\prime}$ terminus, leading to the proposal that the function of Estlp is to mediate association of the 3 ' terminus of the telomere with the Est2p active site. This may be essential for telomerase function in vivo, as null mutants of EST 1 and EST2 have identical phenotypes (Lendvay et al. 1996); however, a test of this proposal will rely on the identification and phenotypic characterization of mutations of EST1 that are specifically defective for telomeric DNA binding. Estlp also exhibits a nonspecific RN A binding activity in vitro, with no enhanced binding to the TLC 1 telomerase RN A (Virta-Pearlman et al. 1996), although this lack of specificity could be the result of incorrect folding of the 1.3-kb yeast telomerase RN A or the lack of another protein binding partner. $\mathrm{N}$ one of these data currently distinguish between Est1p performing its function as a subunit of the enzyme or alternatively as a component of telomeric chromatin required to load telomerase onto the chromosomal terminus. For example, a bona fide interaction between Estlp and the telomerase RN A could still be a consequence of a contact between tel omerase and telomere-bound Estlp, as part of a telomeraseloading activity.

A comparison of the in vitro properties of the yeast Est1 protein with those of the Tetrahymena p95 protein also invoke potential parallels. Despite a lack of primary sequence similarity, both proteins exhibit sequence-specific, low affinity, binding to single-strand telomeric DNA substrates, as well as nonspecific interactions in vitro with RN A (Virta-Pearlman et al. 1996; Gandhi and Collins 1998). This resemblance could indicate that Est1p, as proposed for p95, provides a specific site on the telomerase holoenzyme for primer binding that is separate from the telomerase active site. This model, of course, raises the question of why extracts that completely lack the Est1 protein still retain telomerase activity. However, mutant extracts have currently only been examined with saturating primer concentrations, potentially masking a requirement for Estlp in optimal telomerase activity. Similarly, if Estlp manifests its role as a component of telomeric chromatin, the use of naked DNA primers in the current telomerase assay rather than chromatin-bound DNA substrates would also fail to assess such a function. Biochemical experiments are in progress to investigate these possibilities.

Information about the specific role of the Est3 protein in telomere replication is not yet available, although the Est3 protein exhibits EST2-dependent association with the telomerase RN A, arguing that Est3 interacts directly with the enzyme (T. Hughes and V. Lundblad, unpubl.). The 20-kD Est3 protein has no discernible motifs or homologs in the database, and shows no sequence similarity to any of the telomerase-associated proteins identified in the ciliate systems. Characterization of how the EST3 gene synthesizes its protein product has revealed an unexpected result, in that the same programmed translational frameshifting mechanism used by yeast retrotransposons is also employed to produce the full length Est3 protein (Morris and Lundblad 1997). EST3 is the first example in yeast of a gene required for cellular growth that uses such a process, and raises questions about a potential connection between retrotransposition and telomere maintenance. Such a link had al ready been provided previously from studies of Drosophila, which unlike most organisms, does not rely on telomerase to maintain its telomeres. Instead, telomere-specific retrotransposons are used to replenish the ends of Drosophila chromosomes (Biessmann et al. 1990; Levis et al. 1993), with one of these elements relying on ribosome frameshifting to maintain its protein product (Danilevskaya et al. 1992). Isolation of EST 3 genes in other organisms will be necessary to determine whether frameshifting is a conserved feature of this telomere replication protein.

Although characterization of such proteins in these three organisms has resulted in one clear-cut convergence (the catalytic subunit of the Euplotes and yeast enzymes), equally striking is the overall lack of homologs. Although recent evi dence suggests that the Tetrahymena telomerase also has a RT catal ytic subunit ( $T$. Bryan and T. Cech; M. Rudd and C.W. Greider; both pers. comm.), it is unclear why the Euplotes enzyme is not associated with p95 and p80-like proteins, nor the Tetrahymena enzyme with a p43 subunit. Particularly curious is the fact there is no obvious p80 yeast homolog detectable by searching the compl eted sequence of the $\mathrm{S}$. cerevisiae genome, even though the identification of human, rat and murine p80 homologs has eliminated the possibility that p80 is a ciliate-specific telomerase protein. This lack of convergence may simply be a technical consequence of how early we are in our understanding of what constitutes a telomerase holoenzyme in any system, with additional components still to be identified in each organism. Alternatively, these differences may be attributable to biological variation; despite the overall conservation of a RT with an intrinsic RNA subunit, telomerases in different organisms clearly need to respond to differing requirements, as exemplified by the substantial species-specific variations in telomere length. For example, Euplotes tel omere length is tightly regulated (28 bp of duplex with a 14-nucleotide G-rich overhang; Klobutcher et al. 1981), whereas telomere length in Tetrahymena and yeast is both longer and less stringently controlled, ranging from $\sim 300$ to 500 bp (Larson et al. 1987; Shampay and Blackburn 1988). Even the structure of the $\mathrm{p} 80$ homolog is not precisely conserved, as the mammalian versi ons are substantial ly larger (230240 kD), suggesting additional as yet undetermined function(s).

\section{The consequences of the absence of telomerase}

An early prediction for the phenotype of telomerase-defective cells was that a telomerase deficiency should not be immediately lethal. This was based on the assump- 
tion that loss of a substantial amount of the duplex telomeric G-rich tract could occur before telomere function would be compromised, a premise that was first experimentally verified in the unicellular yeasts. As was initially shown for the $\mathrm{S}$. cerevisiae est ${ }^{-}$mutant, S. cerevisiae, K. lactis, and S. pombe strains defective for the telomerase pathway are initially viable, but the resulting telomere shortening leads to eventual cellular senescence in each of these experimental organisms (Lundblad and Szostak 1989; Singer and Gottschling 1994; M cEachern and Blackburn 1995; Lendvay et al. 1996; N akamura et al. 1997). One implication of this delayed cell death phenotype is that the structure found at the very terminus of the telomere (and hence the presumed telomere capping function) continues to be maintained in the absence of telomerase (Wellinger et al. 1996); proteins that maintain the protective telomeric cap are considered in the last section of this review.

These studies also demonstrated that a defect in telomere replication was sufficient to impose a finite life span on the normally immortal growth characteristics of wild-type yeast. Similarly, although some human cell types with indeterminate proliferative capacity, such as germ-line cells, express telomerase, not all cells sustain an active mechanism to maintain stable telomere length. Telomerase is not detectable in most human somatic cells and presumably as a consequence, telomere length recedes as cells repl icate (Cooke and Smith 1986; Harley et al. 1990; Hastie et al. 1990; Kim et al. 1994). This led to the proposal that the inability to maintain telomere length and/or the terminal structure eventually limits the proliferation of these cells, both in vivo and in cell culture (Olovnikov 1973; Cooke and Smith 1986; Harley 1991). The cloning of the human reverse transcriptase subunit and the demonstration that this component is limiting in normal human cells has allowed a definitive test of this hypothesis, by asking whether stable expression of the hTERT protein extends cell life span in culture. Conversion of two different primary cell types to telomerase-plus results in telomere elongation; more strikingly, these clones fail to exhibit the standard characteristics of senescence after additional propagation (Bodnar et al. 1998). Instead, clones expressing hTERT bypassed the expected senescence point, exceeding their normal life span by at least 20 population doublings. In addition, these extended life span clones have so far maintained a normal karyotype and display the phenotypes associated with young cells. This pivotal result suggests a molecular basis for the long-ago observed $\mathrm{H}$ ayflick limit that di ctates replicative senescence in culture (Hayflick and M oorhead 1961) by showing that restoration of telomerase activity can influence the mitotic cl ock that determines life span. This further supports the concept that reactivation of telomerase may be a primary means to promote immortality during oncogenesis, by removing the short telomere barrier to tumor progression.

An alternative mammalian model that has allowed an examination of the in vivo consequences of a tel omerase deficiency has stemmed from the creation of knockout mice lacking the telomerase RN A subunit (Blasco et al. 1997). The initial striking observations from this experiment are that these mice are not only viable but also fertile for up to six generations, with progeny displaying at least modest telomere shortening as well as an increased incidence of chromosome abnormalities in late generations. Analysis of this mutant strain, however, has been complicated by the fact that the laboratory strain of wild-type Mus musculus mice has extremely long telomeres, reaching lengths $\leqslant 40 \mathrm{~kb}$ (Prowse and Greider 1995). This has necessitated extensive homozygous back-crossing to permit telomere shortening to a length more comparable to that of human cells, with the expectation that phenotypes not evident initially would now become apparent. This approach has in fact revealed that cells that normally display high proliferation rates in the wild-type mouse are now at a disadvantage in the late backcrosses (Lee et al. 1998). This argues that telomere length maintenance plays a role in long-term cellular proliferation not only in cell culture but also in vivo in multicellular organisms.

Expression of telomerase, however, is not the only route to maintaining the ends of linear chromosomes. Experimental studies have shown that in the absence of telomerase, yeast has the ability to mobilize an alternative mechanism for restoring G-rich sequences to the telomere. Although the majority of est ${ }^{-}$mutant cel Is die during extended propagation of the culture, a small subset escape the lethal consequences of a tel omerase deficiency. These survivors arise as a result of recombination-mediated global amplification of telomeric G-rich repeats as well as adjacent subtelomeric regions (Lundbl ad and Blackburn 1993; Lendvay et al . 1996). The effect of this genomic reorganization can be quite dramatic, resulting in up to a 40-fold increase in telomeric G-rich repeats in some cases (as well as an increase in subtelomeric repeats), such that $4 \%$ of the genome consists of telomeric DNA in certain est ${ }^{-}$survivors. Successive rounds of recombination between these expanded telomeres has been proposed as a means of continually replenishing the telomere, whereby telomere structure is now maintained by recombination rather than by tel omerase (Lundbl ad and Blackburn 1993). This process is not specific to telomere replication defects in S. cerevisiae, as a similar telomerase bypass pathway has been observed in K. Iactis (M cEachern and Blackburn 1996), and potential parallels may occur in mammalian cells as well. Both a substantial number of established human cell lines, as well as in vivo tumors, are telomerase-minus, but despite the lack of enzyme activity, telomeres are still exceptionally long (Kim et al. 1994; Bryan et al. 1995, 1997). Although the basis for this alternative mechanism for telomere lengthening (dubbed ALT) has not been elucidated, it further demonstrates that there are nontelomerase options available for chromosome end maintenance. It is also possible that the very long telomeres of $\mathrm{M}$. musculus mice arose at least partly through nontelomerase mechanisms; the telomerase RNA knockout mouse may provide opportunities to examine the contribution of both telomerase and non- 
telomerase based processes to mammalian telomere maintenance.

The above observations come from studies of organisms that normal ly utilize telomerase, but there is also a naturally occurring example of alternative telomere maintenance. Drosophila, used in Muller's pioneering studies to define the telomere, does not employ telomerase and there is no evidence for the G-rich telomeric repeats found in most organisms (Table 1 ) at the ends of Drosophila chromosomes. Instead, the sequence of Drosophila telomeres are a complex pattern of retrotransposable elements, with telomere maintenance apparently due to a balance between gradual loss of DNA and reinsertion of telomere-specific non-LTR retrotransposons (Biessmann et al. 1990; Levis et al. 1993). It is tempting to speculate that this process of telomere maintenance is related to telomerase. Both processes elongate chromosomal termini by the addition of RNAtemplated DNA, and as mentioned above, the RTs of non-LTR retrotransposons and the telomerase reverse transcriptase appear to be both mechanistically and evoIutionarily related (N akamura et al. 1997; Eickbush 1997). If there is a direct relationship, phylogenetic arguments do not currently differentiate between whether a retrotransposon-based mechanism replaced Drosophila telomerase, or vice versa. As the details of both processes become available, this may address the potential evolutionary relationship.

\section{Interactions between telomerase and proteins that protect the telomere}

A primary function of the telomere, as well as at least a subset of associated proteins, is to protect chromosomal termini from end-to-end fusion and severe telomere erosion. That chromosomes in cells lacking telomerase activity do not immediately undergo gross rearrangements or exhibit instability attests to the presence of a telomerase-independent mechanism operating to prevent such events. Therefore, in parallel with the characterization of telomerase, identification of the protein(s) responsible for providing the protective cap function of telomeres has been an area of intense investigation. These capping proteins also have the potential to interact, either directly or indirectly, with telomerase and regulate its activity. Conversely, because tel omerase is responsible for generating the G-rich telomeric repeat tract to which telomeric proteins bind, this suggests the possibility of a dynamic and highly complex set of regulatory interactions.

In a wide vari ety of organisms, a specific structure has been observed at chromosomal termini, with the G-rich strand protruding as a singl e strand extension (Wellinger and Sen 1997). In several different species, this structure has been shown to be complexed with proteins, one or more of which could conceivably contribute to the hypothesized protective telomeric cap. The first singlestrand end binding proteins to be characterized in detail have, like telomerase, been recovered from the ciliates. These activities, best studied in Oxytricha and Euplotes, bind tenaciously to single-strand telomeric repeats and are terminus-specific in vivo and in vitro (Fang and Cech 1995). Physical evidence supporting the hypothesis that these proteins form a protective structure is the resistance of bound tel omeric DN A to nuclease digestion and chemical modification (Gottschling and Zakian 1986; Price and Cech 1987). Terminal proteins such as these also have the potential to interact or compete with telomerase, regulating its activity, but the limitations of ciliate genetics have prevented an in vivo test of either proposed role.

In yeast, both in vivo and in vitro data suggest a function at the telomeric terminus for two single-strand telomeric DN A binding proteins, Est1 and Cdc13. However, although Est1 fulfills the biochemical criteria for a terminus-specific tel omere binding protein, its mutant phenotype suggests that it has no more of a role in chromosome end protection than does EST2 (Virta-Pearlman et al. 1996; Lendvay et al. 1996). A far better candidate for a yeast end-binding activity is the $\mathrm{Cdc} 13$ protein. First identified in Hartwell's classic cell division cycle collection of mutants (Hartwell and Smith 1985), the absence of CDC 13 function results in catastrophic and immediate loss of sequences from the C-strand of the telomere (Garvik et al. 1995). Consistent with a role in maintaining telomere integrity, Cdc13p binds single-strand telomeric DN A in vitro (Lin and Zakian 1996; N ugent et al. 1996). The function of CDC13 goes beyond tel omere protection: The characterization of additional alleles of CDC 13 argues for a complex regulatory interaction with telomerase as well. The cdc13-2 $2^{\text {est }}$ allele, isolated in the screen that identified the EST genes, exhibits the same in vivo telomerase deficiency as other est mutants (Lendvay et al. 1996; Nugent et al. 1996), although enzyme activity is still present in vitro (Lingner et al. 1997b). This has led to the model that $\mathrm{Cdc} 13$ plays a dual role at the tel omere: It not only provides end-binding protection but has a separate role in positively regulating access of telomerase to the chromosomal terminus (N ugent et al. 1996). The phenotypes of yet a third type of mutation in CDC13, which results in greatly elongated telomeres, argue that CDC13 also mediates not only positive regulation but also negative regulation of telomere length ( $T$. Hughes and V. Lundblad, unpubl.). This initial analysis of CDC13 has already provided a picture of a protein that, in its proposed position at the chromosome terminus, participates in an intricate set of interactions involving both tel omere length maintenance and tel omere protection.

Although proteins that bind to the very terminus are the most logical candidates for providing the "cap", recent work from the de Lange laboratory has provided striking evidence that proteins bound to the duplex portion of the telomere play a pivotal role in protecting chromosome ends from fusion (van Steensel et al. 1998). Two TTAGGG repeat binding factors, TRF1 and TRF2, have been characterized previously in human cells (Chong et al. 1995; Bilaud et al. 1997; Broccoli et al. 1997). TRF1, a homodimeric protein with a Myb-like DN A binding domain, is a negative regulator of tel omere 
length and has been proposed to control telomere elongation via cis-mediated inhibition of telomerase (van Steensel and de Lange 1997). TRF2 has a similar Myb motif and also binds human duplex telomeric repeats in vitro, but is distinguished from TRF1 by its amino-terminal domain (Bilaud et al. 1997; Broccoli et al. 1997). Overexpression of dominant-negative al leles of TRF2 in human cells results in loss of terminal single-strand 3' overhangs (although the duplex stretch of TTAGGG repeats is retained), with an accompanying sharp increase in the frequency of end-to-end chromosome fusions (van Steensel et al. 1998). In addition to protection against chromosome end fusions, TRF2 also affects the proliferative potential of cells, as expression of mutant TRF2 proteins leads to irreversible growth arrest of human fibrosarcoma cells, resulting in a senescence-like phenotype (van Steensel et al. 1998). These observations indicate that TRF2 is a key mediator of the loss of telomere function and growth arrest that result from telomere shortening due to the absence of telomerase. This also raises the intriguing question of whether duplex telomere binding proteins in other organisms may play simiIar roles.

\section{Perspectives}

The past several years have seen substantial advances in our understanding of how organisms with linear chromosomes replicate their ends. Central to this progress has been the discovery of the catalytic subunit of telomerase. A remarkable consequence of this finding has been the realization that a reverse transcriptase plays an essential role in chromosomal replication and cellular growth. Equally important, this now provides the foundation for a complete understanding of the telomerase complex. In parallel, the characterization of a number of telomerase-associated proteins promises to extend studies of the tel omerase holoenzyme. The identification of these proteins will allow the field to tacklethe next challenges: unraveling the precise mechanism of telomerase catalysis, understanding the means by which tel omerase activity is regulated, and determining the rel evant factors that allow telomeres to contribute to chromosome transmission.

However, although the excitement of the last few years has focused heavily on telomerase, the novel mechanism of telomere maintenance in Drosophila and the ready appearance of tel omerase bypass pathways indicates that a cell can find alternative ways to maintain its termini, when faced with the selective pressure of replicating its genome. This certainly raises the question of how many other telomere maintenance mechanisms are used by less widely studied research organisms. Just as studies in Tetrahymena were judged (erroneously) early on to be novelty items, delving into the terminal structures of organisms that deviate from the tel omerase norm may be where the new discoveries await.

In human cells, the data suggest that attrition of telomeres may impose a limit upon cell proliferation, presenting a barrier to tumor cell growth. Although the mo- lecular details of how telomere length might signal a tumor suppressor system are still uncl ear, the TRF2 protein appears to play a pivotal role in this process. It seems reasonable to propose that mammalian end binding protein(s) similar to the yeast $\mathrm{Cdc13}$ protein will al so be involved, as well as other telomere-localized proteins yet to be identified. Future detailed understanding of the factors that regulate this process will be critical not only for telomere biologists but also for those who want to apply such findings to research on cancer and aging.

\section{Acknowledgments}

We are grateful to Janice Pata, Phil Hastings, Titia de Lamge, and Tom Cech for insightful discussions and critical reading of the manuscript. Work in our laboratory is supported by grants from the $\mathrm{N}$ ational Institutes of Health, the Geron Corporation, and by a grant to C.N . from the U.S. Army Breast Cancer Research Fund.

\section{References}

Arnold, E., A. Jacobo-M olina, R. Nanni, R. Williams, X. Lu, J. Ding, A.J. Clark, A. Zhang, A. Ferris, P. Clark, A. Hizi, and S. Hughes. 1992. Structure of HIV-1 reverse transcriptase/ DNA complex at $7 \AA$ resolution showing active site locations. Nature 357: 85-89.

Autexier, C. and C.W. Greider. 1994. Functional reconstitution of wild-type and mutant Tetrahymena telomerase. Genes \& Dev. 8: 563-575.

- - - 1995. Boundary el ements of the Tetrahymena telomerase RNA template and alignment domains. Genes \& Dev. 9: 2227-2239.

- - - 1998. Mutational analysis of the Tetrahymena telomerase RN A: Identification of residues affecting telomerase activity in vitro. Nucleic Acids Res. 26: 787-795.

Autexier, C., R. Pruzan, W.D. Funk, and C.W. Greider. 1996. Reconstitution of human telomerase activity and identification of a minimal functional region of the human telomerase RN A. EMBO J. 15: 5928-5935.

Beattie, T., W. Zhou, M. Robinson, and L. Harrington. 1998. Reconstitution of telomerase activity in vitro. Curr. Biol. 8: 177-180.

Bhattacharyya, A. and E.H. Blackburn. 1994. Architecture of telomerase RN A. EMBO J. 13: 5721-5723.

-_- . 1997. A functional tel omerase RN A swap in vivo reveals the importance of nontemplate RNA domains. Proc. Natl. Acad. Sci. 94: 2823-2827.

Biessmann, H., J.M. M ason, K. Ferry, M. d'Hulst, K. Val gei rsdottir, K.L. Traverse, and M.L. Pardue. 1990. Addition of telomere-associated HeT DN A sequences "heals" broken chromosome ends in Drosophila. Cell 61: 663-673.

Bilaud, T., C. Brun, K. Ancelin, C.E. Koering, T. Laroche, and E. Gilson. 1997. Telomeric localization of TRF2, a novel human telobox protein. Nature Genet. 17: 236-239.

Blasco, M.A., W. Funk, B. Villeponteau, and C.W. Greider. 1995. Functional characterization and developmental regulation of mouse telomerase RN A. Science 269: 1267-1270.

Blasco, M., H. Lee, M. Hande, E. Samper, P. Lansdorp, R. DePinho, and C. Greider. 1997. Tel omere shortening and tumor formation by mouse cells lacking telomerase RNA. Cell 91: 25-34.

Bodnar, A.G., M. Ouellette, M. Frolkis, S.E. Holt, C.-P. Chiu, 
G.B. Morin, C.B. Harley, J.W. Shay, S. Lichtsteiner, and W.E. Wright. 1998. Extension of life-span by introduction of telomerase into normal human cells. Science 279: 349-352.

Boyer, P., A. Ferris, P. Clark, J. Whitmer, P. Frank, C. Tantillo, E. Arnold, and S. Hughes. 1994. Mutational analysis of the fingers and palm subdomains of human immunodeficiency virus type-1 (HIV-1) reverse transcriptase. J. Mol. Biol. 243: 472-483.

Broccoli, D., A. Smogorzewska, L. Chong, and T. de Lange. 1997. Human telomeres contain two distinct Myb-related proteins, TRF1 and TRF2. Nature Genet. 17: 231-235.

Brun, C., S. M arcand, and E. Gilson. 1997. Proteins that bind to doublestranded regions of telomeric DNA. Trends Cell. Biol. 7: 317-324.

Bryan, T.M., A. Englezou, J. Gupta, S. Bacchetti, and R.R. Reddel. 1995. Telomere elongation in immortal human cells without detectable telomerase activity. EMBO J. 14: 42404248.

Bryan, T., A. Englezou, L. Dalla-Pozza, M. Dunham, and R. Reddel. 1997. Evidence for an alternative mechanism for maintaining telomere length in human tumors and tumorderived cell lines. Nature Med. 3: 1271-1274.

Chong, L., B. van Steensel, D. Broccoli, H. Erdjument-Bromage, J. Hanish, P. Tempst, and T. de Lange. 1995. A human telomeric protein. Science 270: 1663-1667.

Cohn, M. and E.H. Blackburn. 1995. Telomerase in yeast. Science 269: 396-400.

Collins, K. and C.W. Greider. 1993. Tetrahymena telomerase catalyzes nucleolytic cleavage and nonprocessive elongation. Genes \& Dev. 7: 1364-1376.

Collins, K., R. Kobayashi, and C.W. Greider. 1995. Purification of Tetrahymena telomerase and cloning of genes encoding the two protein components of the enzyme. Cell 81: 677686.

Cooke, H. and B. Smith. 1986. Variability at the tel omeres of the human $X / Y$ pseudoautosomal region. Cold Spring Harb. Symp. Quant. Biol. 51: 213-219.

Counter, C.M., M. Meyerson, E.N . Eaton, and R.A. Weinberg. 1997. The catalytic subunit of yeast telomerase. Proc. Natl. Acad. Sci. 94: 9202-9207.

Danilevskaya, O.N., D.A. Petrov, M.N. Pavlova, A. Koga, E.V. Kurenova, and D.L. Hartl. 1992. A repetitive DN A element, associated with telomeric sequences in Drosophila melanogaster, contains open reading frames. Chromosoma 102: 3240.

Eickbush, T.H. 1997. Telomerase and retrotransposons: Which came first? Science 277: 911-912.

Fang, G. and T. Cech. 1995. Telomere proteins. In Telomeres (ed. E.H. Blackburn and C.W. Grieder), pp. 69-105. Cold Spring Harbor Laboratory Press, Cold Spring Harbor, NY.

Feng, J., W.D. Funk, S.S. Wang, S.L. Weinrich, A.A. Avilion, C.P. Chiu, R.R. Adams, E. Chang, R.C. Allsopp, J. Yu et al. 1995. The RNA component of human telomerase. Science 269: 1236-1241.

Garvik, B., M. Carson and L. Hartwell. 1995. Single-stranded DN A arising at telomeres in cdc13 mutants may constitute a specific signal for the RAD9 checkpoint. Mol. Cell. Biol. 15: 6128-6138.

Ghandi, L. and K. Collins. 1998. Interaction of recombinant Tetrahymena telomerase proteins p80 and p95 with telomerase RNA and telomeric DNA substrates. Genes \& Dev. 12: 721-733.

Gilley, D. and E.H. Blackburn. 1996. Specific RNA residue interactions required for enzymatic functions of Tetrahymena telomerase. Mol. Cell. Biol. 16: 66-75.
Gilley, D., M.S. Lee, and E.H. Blackburn. 1995. Altering specific telomerase RN A template residues affects active site function. Genes \& Dev. 9: 2214-2226.

Gottschling, D. and V. Zakian. 1986. Telomere proteins: Specific recognition and protection of the natural termini of Oxytricha macronuclear DNA. Cell 47: 195-205.

Greider, C.W. 1991. Telomerase is processive. Mol. Cell. Biol. 11: 4572-4580.

Greider, C.W. and E.H. Blackburn. 1985. Identification of a specific telomere terminal transferase activity in Tetrahymena extracts. Cell 43: 405-413.

- - - 1989. A telomeric sequence in the RN A of Tetrahymena telomerase required for telomere repeat synthesis. Nature 337: 331-337.

Hammond, P.W., T.N . Lively, T.N . Lively, and T.R. Cech. 1997. The anchor site of telomerase from Euplotes aediculatus revealed by photo-cross-linking to single- and doublestranded DN A primers. Mol. Cell. Biol. 17: 296-308.

Harley, C.B. 1991. Telomere loss: M itotic clock or genetic time bomb? Mutat. Res. 256: 271-282.

Harley, C.B., A.B. Futcher, and C.W. Greider. 1990. Telomeres shorten during ageing of human fibroblasts. Nature 345: 458-460.

Harrington, L.A. and C.W. Greider. 1991. Telomerase primer specificity and chromosome healing. Nature 353: 451-454.

Harrington, L., C. Hull, J. Crittenden, and C. Greider. 1995. Gel shift and UV cross-linking analysis of Tetrahymena telomerase. J. Biol. Chem. 270: 8893-8901.

Harrington, L., T. McPhail, T. McPhail, V. Mar, W. Zhou, R. Oulton, M.B. Bass, I. Arruda, and M.O. Robinson. 1997a. A mammalian telomerase-associated protein. Science 275: 973-977.

Harrington, L., W. Zhou, T. McPhail, R. Oulton, D.S.K. Yeung, V. Mar, M.B. Bass, and M.O. Robinson. 1997b. Human telomerase contains evolutionarily conserved catalytic and structural subunits. Genes \& Dev. 11: 3109-3115.

Hartwell, L. and D. Smith. 1985. Altered fidelity of mitotic chromosome transmission in cell cycle mutants of S. cerevisiae. Genetics 110: 381-395.

Hastie, N., M. Dempster, M. Dunlop, A. Thompson, D. Green, and R. Allshire. 1990. Telomere reduction in human colorectal carcinoma and with aging. Nature 346: 866-868

Hayflick, L. and P. Moorhead. 1961. The serial cultivation of human diploid strains. Exp. Cell Res. 25: 585-621.

Hinkley, C.S., M.A. Blasco, W.D. Funk, J. Feng, B. Villeponteau, C.W. Greider, and W. Herr. 1998. The mouse telomerase RNA $5^{\prime}$ end lies just upstream of the telomerase template sequence. Nucleic Acid Res. 26: 532-536.

Jacobo-M olina, A., J. Ding, R.G. N anni, A.D. Clark, Jr, X. Lu, C. Tantillo, R.L. Williams, G. Kamer, A.L. Ferris, P. Clark, A. Hizi, S.H. Hughes, and E. Arnold. 1993. Crystal structure of human immunodeficiency virus type I reverse transcriptase complexed with double-stranded DNA at $3.0 \AA$ resolution shows bent DNA. Proc. Natl. Acad. Sci. 90: 6320-6324.

Kilian, A., D.D. Bowtell, H.E. Abud, G.R. Hime, D.J. Venter, P.K. Keese, E.L. Duncan, R.R. Reddel, and R.A. Jefferson. 1997. Isolation of a candidate human telomerase catalytic subunit gene, which reveals complex splicing patterns in different cell types. Hum. Mol. Genet. 6: 2011-2019.

Kim, N.W., M.A. Piatyszek, K.R. Prowse, C.B. Harley, M.D. West, M.D. West, P.L. Ho, G.M. Coviello, W.E. Wright, S.L. Weinrich, and J.W. Shay. 1994. Specific association of human telomerase activity with immortal cells and cancer. Science 266: 2011-2015.

Klobutcher, L.A., M.T. Swanton, P. Donini, and D.M. Prescott. 1981. All gene-sized DNA molecules in four species of hy- 
potrichs have the same terminal sequence and an unusual 3' terminus. Proc. Natl. Acad. Sci. 78: 3015-3019.

Kohlstaedt, L.A., J. Wang, J.M. Friedman, P.A. Rice, and T.A. Steitz. 1992. Crystal structure at $3.5 \AA$ resolution of HIV-1 reverse transcriptase complexed with an inhibitor. Science 256: 1783-1790.

Kramer, K.M. and J.E. Haber. 1993. N ew telomeres in yeast are initiated with a highly sel ected subset of T G1-3 repeats. Cell 75: 1083-1093.

Larder, B., D. Purifoy, K. Powell, and G. Darby. 1987. Site-specific mutagenesis of AIDS virus reverse transcriptase. $\mathrm{Na}$ ture 327: 716-717.

Larson, D.D., E.A. Spangler, E.A. Spangler, and E.H. Blackburn. 1987. Dynamics of telomere length variation in Tetrahymena thermophila. Cell 50: 477-483.

Lee, M.S. and E.H. Blackburn. 1993. Sequence-specific DNA primer effects on telomerase polymerization activity. Mol. Cell. Biol. 13: 6586-6599.

Lee, H.-W., M.A. Blasco, G.J. Gottlieb, J.W. Horner, C.W. Greider, and R.A. DePinho. 1998. Essential role of mouse telomerase in highly proliferative organs. $\mathrm{N}$ ature (in press).

Lendvay, T.S., D.K. M orris, J. Sah, B. Balasubramanian, and V. Lundblad. 1996. Senescence mutants of Saccharomyces cerevisiae with a defect in telomere replication identify three additional EST genes. Genetics 144: 1399-1412.

Levis, R.W., R. Ganesan, K. Houtchens, L.A. Tolar, and F.-M. Sheen. 1993. Transposons in place of telomeric repeats at a Drosophila telomere. Cell 75: 1083-1093.

Lin, J.J. and V.A. Zakian. 1995. An in vitro assay for Saccharomyces tel omerase requires EST 1. Cell 81: 1127-1135.

- - 1996. The Saccharomyces CDC13 protein is a singlestrand $\mathrm{TG}_{1-3}$ telomeric DNA-binding protein in vitro that affects telomere behavior in vivo. Proc. Natl. Acad. Sci. 93: $13760-13765$.

Lingner, J. and T.R. Cech. 1996. Purification of telomerase from Euplotes aediculatus: Requirement of a primer 3' overhang. Proc. Natl. Acad. Sci. 93: 10712-10717.

Lingner, J., L.L. Hendrick, and T.R. Cech. 1994. Telomerase RNAs of different ciliates have a common secondary structure and a permuted template. Genes \& Dev. 8: 1984-1998.

Lingner, J., T.R. Hughes, A. Shevchenko, M. Mann, V. Lundblad, and T.R. Cech. 1997a. Reverse transcriptase motifs in the catalytic subunit of telomerase. Science 276: 561-567.

Lingner, J., T.R. Cech, T.R. Hughes, and V. Lundblad. 1997b. Three Ever Shorter Tel omere (EST) genes are dispensable for in vitro yeast telomerase activity. Proc. Natl. Acad. Sci. 94: 11190-11195.

Lundblad, V. and E.H. Blackburn. 1993. An alternative pathway for yeast telomere maintenance rescues est $1^{-}$senescence. Cell 73: 347-360.

Lundblad, V. and J.W. Szostak. 1989. A mutant with a defect in telomere elongation leads to senescence in yeast. Cell 57: 633-643.

McClintock, B. 1941. The stability of broken ends of chromosomes in Zea mays. Genetics 26: 234-282.

- - - 1942. The fusion of broken ends of chromosomes following nuclear fusion. Proc. Natl. Acad. Sci. 28: 458-463.

McCormick-Graham, M. and D.P. Romero. 1996. A single telomerase RNA is sufficient for the synthesis of variable tel omeric DNA repeats in ciliates of the genus Paramecium. Mol. Cell. Biol. 16: 1871-1879.

McCormick-Graham, M., W.J. Haynes and D.P. Romero. 1997. Variable telomeric repeat synthesis in Paramecium tetraurelia is consistent with misincorporation by telomerase. EMBO J. 16: 3233-3242.

McEachern, M.J. and E.H. Blackburn. 1994. A conserved se- quence motif within the exceptionally diverse tel omeric sequences of budding yeasts. Proc. Natl. Acad. Sci. 91: 34533457.

_-_. 1995. Runaway tel omere el ongation caused by telomerase RN A gene mutations. Nature 376: 403-409.

-_- 1996. Cap-prevented recombination between terminal tel omeric repeat arrays (tel omere CPR) maintains tel omeres in Kluyveromyces lactis lacking telomerase. Genes \& Dev. 10: 1822-1834.

Melek, M., E.C. Greene, and D.E. Shippen. 1996. Processing of nontel omeric 3 ' ends by telomerase: Default template alignment and endonucleolytic cleavage. Mol. Cell. Biol. 16: 3437-3445.

Meyerson, M., C.M. Counter, E.N. Eaton, L.W. Ellisen, P. Steiner, S.D. Caddle, L. Ziaugra, R.L. Beijersbergen, M.J. Davidoff, Q. Liu, S. Bacchetti, D.A. Haber, and R.A. Weinberg. 1997. hEST 2, the putative human tel omerase catalytic subunit gene, is up-regulated in tumor cells and during immortalization. Cell 90: 785-795.

Morin, GB. 1989. The human telomere terminal transferase enzyme is a ribonucleoprotein that synthesizes TTAGGG repeats. Cell 59: 521-529.

_-_. 1991. Recognition of a chromosome truncation site associated with al pha-thal assaemia by human tel omerase. $\mathrm{Na}$ ture 353: 454-456.

Morris, D.K. and V. Lundblad. 1997. Programmed translational frameshifting in a gene required for yeast telomere replication. Curr. Biol. 7: 969-976.

Muller, H.J. 1938. The remaking of chromosomes. Collect. Net-Woods Hole 13: 181-198.

Nakamura, T.M., G.B. Morin, K.B. Chapman, S.L. Weinrich, W.H. Andrews, J. Lingner, C.B. Harley, and T.R. Cech. 1997. Telomerase catalytic subunit homologs from fission yeast and human. Science 277: 955-959.

N akayama, J., M. Saito, H. N akamura, A. M atsuura, and F. Ishikawa. 1997. TLP1: A gene encoding a protein component of mammalian telomerase is a novel member of WD repeats family. Cell 88: 875-884.

Nakayama, J., H. Tahara, E. Tahara, M. Saito, K. Ito, H. Nakamura, T. N akanishi, E. Tahara, T. Ide, and F. Ishikawa. 1998. Telomerase activation by hTRT in human normal fibroblasts and hepatocellular carcinomas. N ature Genet. 18: 6568.

Nugent, C.I., T.R. Hughes, N.F. Lue, and V. Lundblad. 1996. Cdc13p: A single-strand telomeric DNA-binding protein with a dual role in yeast telomere maintenance. Science 274: 249-252.

Olovnikov, A. 1973. A theory of marginotomy: The incomplete copying of template margin in enzymatic synthesis of polynucleotides and biological significance of the phenomenon. J. Theor. Biol. 41: 181-190.

Prescott, J. and E.H. Blackburn. 1997a. Telomerase RN A mutations in Saccharomyces cerevisiae alter telomerase action and reveal nonprocessivity in vivo and in vitro. Genes \& Dev. 11: 528-540.

-_- 1997b. Functional ly interacting tel omerase RN As in the yeast telomerase complex. Genes \& Dev. 11: 2790-2800.

Price, C.M. and T.R. Cech. 1987. Telomeric DNA-protein interactions of Oxytricha macronuclear DNA. Genes \& Dev. 1: $783-793$.

-_- 1989. Properties of the telomeric DN A-binding protein from Oxytricha nova. Biochemistry 28: 769-774.

Prowse K.R. and C.W. Greider. 1995. Developmental and tissuespecific regulation of mouse tel omerase and tel omere length. Proc. Natl. Acad Sci. 92: 4818-4822.

Prowse, K.R., A.A. Avilion, and C.W. Greider. 1993. Identifica- 
tion of a nonprocessive telomerase activity from mouse cells. Proc. Natl. Acad. Sci. 90: 1493-1497.

Ricchetti, M. and H. Buc. 1996. A reiterative mode of DNA synthesis adopted by HIV-1 reverse transcriptase after a misincorporation. Biochemistry 35: 14970-14983.

Romero, D.P. and E.H. Blackburn. 1991. A conserved secondary structure for telomerase RN A. Cell 67: 343-353.

Sandell, L.L. and V.A. Zakian. 1993. Loss of a yeast telomere: Arrest, recovery, and chromosome loss. Cell 75: 729-739.

Shampay, J. and E.H. Blackburn. 1988. Generation of telomere length heterogeneity in Saccharomyces cerevisiae. Proc. Natl. Acad. Sci. 85: 534-538.

Shampay, J., J.W. Szostak, and E.H. Blackburn. 1984. DNA sequence of telomeres maintained in yeast. Nature 310: 154157.

Shore, D. 1997. Telomere length regulation: getting the measure of chromosome ends. Biol. Chem. 378: 591-597.

Singer, M.S. and D.E. Gottschling. 1994. TLC1: Template RN A component of Saccharomyces cerevisiae telomerase. Science 266: 404-409.

Steiner, B.R., K. Hidaka, and B. Futcher. 1996. Association of the Est1 protein with telomerase activity in yeast. Proc. Natl. Acad. Sci. 93: 2817-2821.

ten Dam, E., A. van Belkum, and K. Pleij. 1991. A conserved pseudoknot in telomerase RNA. Nucleic Acids Res. 19: 6951.

van Steensel, B. and T. de Lange. 1997. Control of telomere length by the human telomeric protein TRF1. Nature 385: 740-743.

van Steensel, B., A. Smogorzewska, and T. de Lange. 1998. TRF2 protects human telomeres from end to end fusions. Cell 92: 401-413.

Virta-Pearlman, V., D.K. Morris, and V. Lundblad. 1996. Est1 has the properties of a single-stranded telomere end-binding protein. Genes \& Dev. 10: 3094-3104.

Wang, S.S. and V.A. Zakian. 1990. Sequencing of Saccharomyces tel omeres cloned using T 4 DN A polymerase reveals two domains. Mol. Cell. Biol. 10: 4415-4419.

Weinrich, S.L., R. Pruzan, L. Ma, M. Ouellette, V.M. Tesmer, S.E. Holt, A.G. Bodnar, S. Lichtsteiner, N.W. Kim, J.B. Trager, R.D. Taylor, R. Carlos, W.H. Andrews, W.E. Wright, J.W. Shay, C.B. Harley, and G.B. Morin. 1997. Reconstitution of human telomerase with the template RN A component hTR and the catalytic protein subunit hTRT. Nature Genet. 17: 498-502.

Wellinger, R.J. and D. Sen. 1997. The DNA structures at the ends of eukaryotic chromosomes. Eur. J. Cancer 33: 735749.

Wellinger R.J., K. Ethier, P. Labrecque, and V. Zakian. 1996. Evidence for a new step in telomere maintenance. Cell 85: 423-433.

Xiong, Y. and T.H. Eickbush. 1990. Origin and evolution of retroelements based upon their reverse transcriptase se quences. EMBO J. 9: 3353-3362.

Yu, G.-L. and E.H. Blackburn. 1991. Developmentally programmed healing of chromosomes by telomerase in Tetrahymena. Cell 67: 823-832.

Yu, G.L., J.D. Bradley, L.D. Attardi and E.H. Blackburn. 1990. In vivo al teration of tel omere sequences and senescence caused by mutated Tetrahymena telomerase RNAs. Nature 344: 126-132.

Zaug, A.J. and T.R. Cech. 1995. Analysis of the structure of Tetrahymena nuclear RNAs in vivo: Telomerase RNA, the self-splicing rRN A intron, and U2 snRNA. RNA 1: 363-374. 


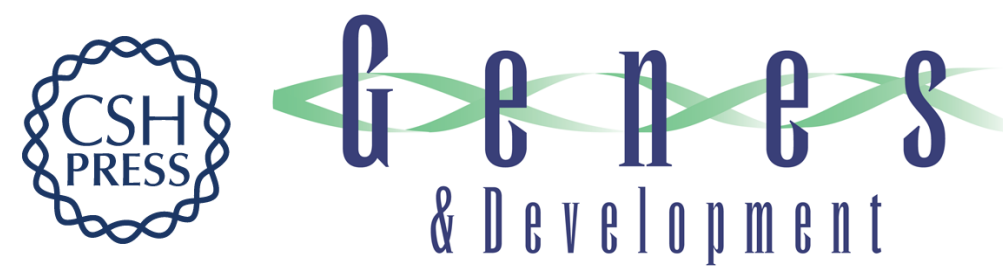

\section{The telomerase reverse transcriptase: components and regulation}

Constance I. Nugent and Victoria Lundblad

Genes Dev. 1998, 12:

References This article cites 103 articles, 52 of which can be accessed free at: http://genesdev.cshlp.org/content/12/8/1073.full.html\#ref-list-1

License

Email Alerting

Receive free email alerts when new articles cite this article - sign up in the box at the top Service right corner of the article or click here.

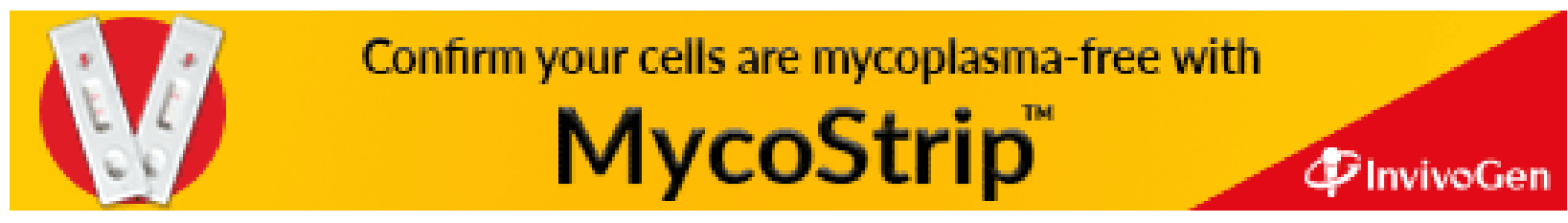

